for the first 44 pages should be compulsory reading for anyone hoping to control mealybugs. Professor McKenzie's monograph will become the most consulted book on mealybugs.

V. F. EASTOP

\section{PARTICLES AND FIELDS}

\section{Proceedings of the 1967 International Conference on Particles and Fields}

The University of Rochester, Rochester, New York, August 28-September 1, 1967. Edited by C. R. Hagen, G. Guralnik and V. S. Mathur. Pp. 707. (New York and London: Interscience Publishers, a Division of John Wiley and Sons, 1967.) 94s.

THE 1967 conference to which these proceedings belong was not one of the regular international conferences on high energy physies, which in fact took place in Heidelberg later that year. As stated in the foreword ". . . the purpose of the Rochester Conference was to provide a forum for an intensive examination of several key problems of particle physics ...". To this end, the summary talks of the first session, which were devoted to the latest experimental developments in the field, formed the necessary prelude to the detailed theoretical talks which succeeded in the romaining six sessions. Much of the material of the book (except perhaps the session concerned with infinite representations of particles) was repoated and enlarged on at Heidelberg the following month and it has since also appeared in print (North-Holland, 1968). For those of us who have to choose between these two conference proceedings, one must obviously recommend the later Heidelberg publication, which eontains a newer and more comprehensive coverage of the experimental results. Nevertheless, those who would like to savour the flavour of a physics conference will thoroughly enjoy the discussions which followed the scheduled talks at Rochester; exceptionally spicy were Kallen's comments about the work of Feynman and Schwinger. R. Delbourco

\section{INFRARED}

\section{Essentials of Modern Physics Applied to the Study of the Infrared}

By Armand Hadni. (International Series of Monographs in Infrared Science and Technology, Vol. 2.) Pp. xvi +728. (Oxford, London and New York: Pergamon Press, 1967.) $195 s$.; $\$ 24$.

WITHrN a period of about twenty-five years infrared studies have been totally transformed. The pioneer's home-made point-by-point spectrometer, using a sensitive galvanometer, has grown into the farmiliar rugged and automatic rocording instrument in everyday use. In the past few years new developments have put the far infrared into the hands of chemists. In physics, current infrared studies include investigations of semi-conductors and phonon processes in crystals. The recent development of the infrared laser and the wide applications it is already receiving are indications that the field of infrared studies is likely to continue to be an active one. It is in this context that Professor Armand Hadni's comprehensive text on the infrared is both appropriate and welcome. Although the book includes in its coverage basic theory of radiation with special reference to infrared, it is likely to be particularly valuable to those concerned with experimental techniques and instrumentation in the infresred.

The opening chapter, on instrumental opties in the infrared, deals in some detail with prism and grating dispersion, and also multiplex spectrometry; particular attention is given to the problem of eliminating stray light. The second chapter on sources of infrared gives a general account of emission of radiation. Thermal errission receives a good deal of attention, but atomic and molecular spectral emission. lasers and generation of radiation by electrical circuits are all discussed. The next chapter, which is on infrared detectors, provides an account of the physies underlying the various types of thermal detectors, photoconductive cells and other quantum detectors. After a chapter on propagation of electromagnetic waves, polarization, dielectric constant and dispersion, there follows a chapter on the physics of vibrations in erystals which has special reference to interaction with infrared radiation. Finally, there is a chapter on developments in far infrared spectroscopy, a field to which Professor Hadni has contributed much himself. Both instrumentation and the different types of transition which give rise to spectra in this region are discussed. Each chapter is followed by a bibliography, complet: up to October 1966, and comprising in all more than a thousand references.

D). J. MHLLEX

\section{PYRROLES AND PYRIDINES}

\section{Hetero-Aromatic Nitrogen Compounds}

Pyrroles and Pyridines. By K. Schofield. Pp. viii +434. (London: Butterworth and Co. (Publishers). Ltd. I967.) $120 s$.

'I'He contents and the price of this hook indicate that it is primarily intended for graduate students and researeh workers whose major interest is in heterocyclic chemistry. It is, however, an ideal reference book for undergraduate students and its absence from any library would leave at serious gap in the literature of pyrroles and pyridines. The first three chapters constitute an introductory section which describes the historical background as well as the modern ideas of the structure and reactivity of aromatic compounds in general and of pyrrole and pyridine in particular. One may criticize this section as being too elementary in places and somewhat superfluous particularly in view of the intended standard of the reader. The introductory section, however, leads smoothly into the second section, which, in a further three chapters, describes the physical and chemical properties of the pyrrole and pyridine nuclei and their derivatives.

'The chemistry of pyridine and its derivatives is particularly well described in just under 300 pages and this section compares very favourably with considerably more voluminous and more costly texts which are available. The chemistry of pyrrole is dismissed in a mere 68 pages. One feels that Dr Schofield has been more selective in his choice of presentable data, particularly in the tables, for pyrroles than he has for pyridines, and one may question. the usefulness of tables which are not comprehensive. In spite of its brevity, however, the chapter on the chernistry of pyrrole is considerably better than any text which is available at present.

Both sections of the book are well supported by references to the original literature and cross-references within the book are also provided. I, however, found some difficulty in locating specific facts within the text, partly because of the somewhat inadequate nature of tho subject index, but mainly because of the general manner in which the book has been written. Often it is necessary to refer to several different parts of the book to obtain a complete understanding of a particular piece of informa. tion. Also, one or two of the !cross-references appear to have gone astray. 'The index to substitution reartions of pyridines was found to be particularly useful and a similar table for the reactions of pyrrols would have been of use in the rapid location of information.

Errors and omissions in the text are rare and, in general, quite trivial. In spite of Dr Schofield's contention, however, of "arguments about the naming of tautomeric systems . . to be stcrile", I am of the opinion that 